\title{
Regional Differences and Convergence Analysis of Green Energy Efficiency in China
}

\author{
Xiaoyu Liu, Hao Li ${ }^{*}$ \\ School of statistics, Jiangxi university of Finance and Economics, Nanchang, China \\ Email: ^18720070195@163.com
}

How to cite this paper: Liu, X.Y. and $\mathrm{Li}, \mathrm{H}$. (2018) Regional Differences and Convergence Analysis of Green Energy Efficiency in China. Journal of Power and Energy Engineering, 6, 48-58. https://doi.org/10.4236/jpee.2018.66004

Received: May 28, 2018

Accepted: June 25, 2018

Published: June 28, 2018

Copyright ( $) 2018$ by authors and Scientific Research Publishing Inc. This work is licensed under the Creative Commons Attribution International License (CC BY 4.0).

http://creativecommons.org/licenses/by/4.0/

(c) (i) Open Access

\begin{abstract}
As an important aspect for the survival and development of human society, energy is an important factor that restricts the economic and social development of a country. This paper measured the green energy efficiency of thirty provinces of China from 2000 to 2016 by using the Super-SBM, introducing it to the spatial economic model to study the convergence of green energy efficiency. The results show that: the overall green energy efficiency of China shows a downward trend with time, and it gradually decreases from east to west. The three regions have significant differences. Among them, there is no $\beta$ absolute convergence trend for the eastern, central, western regions and the country as a whole, but there is $\beta$ relative convergence. The level of economic development, R \& D investment, the level of technology improvement, and foreign direct investment have positive effects on the development of green energy efficiency. The industrial structure has a positive effect in the eastern but a negative effect in the western.
\end{abstract}

\section{Keywords}

Green Energy Efficiency, Super-SBM, Spatial Econometrics

\section{Introduction}

At present, the energy-use efficiency in China is $33 \%$, far lower than the world average level, which is equivalent to that of developed countries 20 years ago. However, China's energy consumption intensity is much higher than that of developed countries and the world average, about 3 times of the United States and 7 times of Japan. Moreover, as for the energy consumption per unit output value, China is one of the highest countries in the world. Therefore, energy shortage has become the bottleneck of sustainable development in China. Under the increasingly severe background for development, the Chinese government actively 
responded and clearly proposed the development concept of establishing innovation, coordination, green, openness, and sharing in the "Thirteenth Five-Year Plan" outline, adhere to green development, and strive to improve the ecological environment [1]. Under this background, taking full account of energy consumption and environmental governance, and examining regional green energy efficiency and its development trend, are of great theoretical and practical significance to realize sustainable economic development and implement the concept of green development. Green energy efficiency refers to the ability of an economy to maximize the output after comprehensively considering the energy consumption and environmental damage in production activities. That is the ability to maximize output at a given energy consumption, or to minimize energy consumption at a given output level.

In the actual research, energy efficiency is divided into partial factor energy efficiency and total factor energy efficiency according to the input and output factors. Partial factor energy efficiency is often expressed as the ratio of total output value to energy consumption in practical applications. Total factor energy efficiency comprehensively considers the effects of multiple inputs such as energy, labor, and capital on output, making up for the shortcomings of the partial factor energy efficiency (it cannot measure the mutual substitution effect between energy elements and other elements, and cannot reflect the potential technical efficiency of energy utilization.). Hu and Wang defined "total factor energy efficiency" as: in the process of economic growth, under the premise that other factors (such as capital and labor) other than the input of energy remain unchanged, according to the best production practice, the ratio of the target energy input to the actual input. This index is a dimensionless variable and is a positive not greater than 1 [2].

At present, research on energy efficiency mainly focuses on total factor energy efficiency. $\mathrm{Hu}$ and $\mathrm{Li}$ calculated the energy efficiency of 29 Administrative Regions in China by using the data of China from 1995 to 2002 [3]; Xiong and Huang calculated the energy technology efficiency of 34 industrial sectors in China from 1999 to 2008 by using the non-balanced panel data and the maximum likelihood estimation method. What's more, in the paper, they also analyzed the impact mechanism of opening to the outside world. The result showed that the overall energy technology efficiency of China's industrial industry was constantly increasing. However, there are significant differences among different factor-intensive industrial sectors, and the degree of dependence on foreign trade and the participation level of foreign capital have played a positive role in promoting China's industrial energy technology efficiency [4].

In recent years, there has been a breakthrough in the research of energy efficiency. Scholars have started to study technological efficiency from a "green" perspective by considering the environment and resources. $\mathrm{Hu}$, Zheng, Gao, Zhang and $\mathrm{Xu}$ adopted $\mathrm{CO}_{2}, \mathrm{COD}, \mathrm{SO}_{2}$, wastewater discharge, and total solid waste displacement as environmental indicators, which were included in the 
standard DEA (Data Envelopment Analysis) model to measure the technical efficiency of each province (city, district). They also gave the provincial technical efficiency ranking in this work [5]; Wang and Fen select labor force, capital stock, and energy consumption as input indicator variables; regional GDP (Gross Domestic Product) is a consensus output variable, meanwhile, environmental pollution emissions and greenhouse gas emissions as non-consensual output variable. Based on the four-stage DEA principle, using the global DEA-Malmquist-Luenberger expansive model to and further applying the Tobit regression model to study its influencing factors [6]; Zhou and Zhang also added "three industrial wastes", which are closely related to energy consumption and the production function. Using the DEA model with input-oriented and constant returns to scale, which is based on the panel data of all provinces and cities in 2002-2013, to calculate total factor energy efficiency in China's eight major economies [7]; Hongli Yu introduced the concept of green energy efficiency, incorporated non-desired outputs on the basis of traditional energy efficiency measurement models, and built green energy efficiency measurement system that includes both economic and environmental impacts. The system measured the green energy efficiency of each province in the Yangtze River Economic Belt from 2000 to 2015. Through data analysis, it was found that the level of green energy efficiency was higher was higher in the downstream cities than that in the midstream cities, at the same time, the level in midstream cities than in the upstream cities, which is compatible with the development ladder of the Yangtze River Economic Belt. From the longitudinal perspective of the time series, green energy efficiency showed a U-shaped change trajectory over time [8].

The above-mentioned studies about the green energy efficiency are mostly from the perspective of environmental pollution, lack of a comprehensive investigation of green energy efficiency from the perspective of environmental governance, which, however, do not meet the actual production process. Thus, in this paper, we draw on the concept of green GDP accounting and considering both environmental pollution and environmental governance. It constructs an environmental composite index (ECI) to modify traditional output indicators, and uses Super-SBM (Slacks-based Model) to measure the green energy efficiency of China's 30 Administrative Regions. Moreover, we explore regional differences and convergence of green energy efficiency.

\section{Models and Methods}

\subsection{Super-SBM}

DEA is an effective non-parametric method to measure total factor energy efficiency, especially in the evaluation of production efficiency for decision-making units (DMU) with multiple inputs and multiple outputs. The traditional DEA model (such as BCC model, CCR model) is mostly radial or angular, it does not fully consider the relaxation problem of input or output, nor can it accurately measure the efficiency value when there is undesired output [9]. Therefore, Tone 
proposed a non-radial, non-angular SBM, which puts the slack variable directly into the objective function, which not only solves the relaxation problem of input and output, but also solves the evaluation deviation problem in undesired output efficiency [10].

However, when using the SBM to measure the efficiency value, the efficiency of multiple decision units is 1 , which leads to no effective evaluation and ranking between these decision units.

In response to this defect of the SBM, Tone further proposed a Super-SBM for correcting slack variables [11]. The model can further evaluate and rank the effective units of the SBM, that is, allowing the efficiency value to be greater than or equal to 1 . The effective units (decision units with an efficiency equal to 1 in the SBM) can be sorted. The Super-SBM uses the method of replacing the input and output of the $i$ th decision-making unit with a linear combination of input and output of all other decision-making units when evaluating the th decision-making unit, and excludes the ith decision-making unit from the set of decision-making units.

Think of each province as a DMU, assuming that each province has the following input-output vectors: input (including capital, labor, energy consumption, etc.), output (regional GDP), and its elements can be expressed as: $x \in R^{m}$ and $y \in R^{s}$, define the matrix $X$ and $Y$ as follows:

$$
X=\left[x_{1}, \cdots, x_{n}\right] \in R^{m \times n}, Y=\left[y_{1}, \cdots, y_{n}\right] \in R^{s \times n}, x_{i}>0, y_{i}>0
$$

The production possibility set is:

$$
P=\left\{\left(x_{0}, y_{0}\right) \mid x \geq X \lambda, y \leq Y \lambda, \lambda \geq 0\right\}
$$

where $\lambda$ is a weight vector, and if the sum is 1 , it means that the production technology is a variable scale of return (VRS); otherwise, it means a constant scale of return (CRS).

Then define the sub-collection:

$$
\bar{P}=P \cap\left\{(x, y) \mid x \geq x_{0}, y \leq y_{0}\right\}
$$

The Super-SBM can be written as follows:

$$
\rho^{\text {sup }}=\min \frac{\frac{1}{m} \sum_{i=1}^{m} x_{i} / x_{i 0}}{\frac{1}{S} \sum_{r=1}^{s} y_{r} / y_{r 0}}
$$

$$
\text { s.t. }
$$

$$
\begin{aligned}
& x \geq \sum_{\substack{n=1 \\
n \neq i}}^{N} x_{n} \cdot \lambda_{n} ; \\
& y \leq \sum_{\substack{n=1 \\
n \neq i}}^{N} y_{n} \cdot \lambda_{n} ; \\
& x \geq x_{0}, y \leq y_{0}, \lambda \geq 0
\end{aligned}
$$

From the formula (1), it can be calculated that the efficiency value greater than 
or equal to 1, that is, the SBM super-efficiency value, is different from the efficiency value calculated by the ordinary SBM, so that the effective decision-making unit can be further evaluated and sorted. Therefore, this paper uses the Super-SBM to measure the green energy efficiency of each region in the country.

\subsection{Determination of Indicators}

\section{1) Input indicators}

For labor input, this article uses effective labor indicators to represent labor input. The effective labor force in each province = the number of people employed in each province $\times$ (the average number of years of education per province $\div$ the average number of years of education in the country). The equation for calculating the average number of years of education for employees in each province is shown in formula (2). Among them, $i$ stands for different provinces, $j$ stands for 5 types of education (not in primary school, elementary school, junior high school, senior high school, junior college, and above), $H_{i t}$ is the average number of years of education in province $i$ and year $t, e d u_{i t, j}$ is the number of years of education of the th type of education in province $i$, and year $t$ (the number of years of education represented by the five types of education is 3 , $6,9,12$, and 16). $P_{i t, j}$ is the proportion of employment of the $t$ th type of education in total employment in province $i$ and year $t$. Taking into account the fact that no primary school students have received certain training at work, and in order to reflect the gap between different levels of education, this paper takes the value of the number of years of education not in primary schools as 3 . According to the formula (2), the national data can be used to calculate the average number of years of education for the country's employees. The number of employees in each province is measured by the average number of employees in each province.

$$
H_{i t}=\sum_{j=1}^{5} e d u_{i t, j} \times P_{i t, j}
$$

For material capital investment, the annual average capital stock index is used to measure. Because of the vacancy of the public information, this article refers to the research of most scholars and uses the "perpetual inventory method" to estimate the capital stock data for each province from 2000 to 2016 . The specific calculation formula is as shown in formula (3). Among them, $K_{i t}$ and $K_{i t-1}$ are respectively the capital stocks in years $t$ and $t-1$ in $i$ provinces; $\delta_{i t}, I_{i t}$ and $P_{i t}$ are respectively the depreciation rate, the total investment, and the investment price index in province $i$ in year $t$. The calculation of initial capital stock, depreciation rate, and investment price index are all based on the algorithm of Haojie Shan [12]. For the comparability of the study, this paper converted all the data of the capital stocks in the provinces from 2000 to 2016 into 2000 prices.

$$
K_{i t}=K_{i t-1}\left(1-\delta_{i t}\right)+I_{i t} / P_{i t}
$$

For energy input, this paper uses the total energy consumption of each prov- 
ince to represent energy input. The unit is: 10,000 tons of standard coal.

\section{2) Output indicators}

Using the idea of green GDP accounting for reference, this paper uses Zhiping Wang's treatment method to measure the environmental cost in economic development by constructing the environmental comprehensive index (ECI), and adjusts the traditional output indicators to obtain the relative green GDP [13]. The specific steps are as follows: first, select seven indicators $\left(X_{1} \sim X_{7}\right)$ from the perspective of environmental pollution emission and governance to construct an environmental indicator system that reflects the environmental conditions in each region,; then, use factor analysis methods to simplify the indicators and calculate the comprehensive factor scores $S$, which is converted into an environmental comprehensive index (ECI) by formula (5), to measure the environmental costs in each region; finally, the environmental comprehensive index (ECI) multiplied by the GDP of each region is defined as the relative green GDP of each region. Among them, the pollution control investment rate $\left(X_{1}\right)=$ total investment in pollution control / GDP; wastewater discharge compliance rate $\left(X_{2}\right)=$ wastewater discharge compliance / wastewater discharge; $\mathrm{SO}_{2}$ removal rate $\left(X_{3}\right)=\mathrm{SO}_{2}$ removal / $\mathrm{SO}_{2}$ emissions; Industrial Smoke Removal Rate $\left(X_{4}\right)=$ Industrial Smoke Removal / Industrial Smoke Dust; Industrial Dust Removal Rate $\left(X_{5}\right)=$ Industrial Dust Removal / Industrial Dust Discharge; Solid Waste Disposal Rate $\left(X_{6}\right)=$ Solid Waste Disposal / Solid Waste production; the comprehensive utilization indica$\operatorname{tors}\left(X_{7}\right)=$ " three industrial wastes" comprehensive utilization of product output value / industrial pollution control investment. Output indicators are characterized by relative green GDP. In order to eliminate the impact of price factors, the GDP is adjusted by GDP deflator and the year of 2000 as the base year.

$$
\begin{gathered}
E C I=0.5+0.5 \times(S-\min (S)) /(\max (S)-\min (S)) \\
\text { Green GDP }=\mathrm{GDP} \times \mathrm{ECI}
\end{gathered}
$$

\section{3) Data Sources}

This paper selects data from 30 provinces, cities, autonomous regions (excluding Tibet) from 2000 to 2016 for analysis. The data used are mainly derived from the "China Statistical Yearbook", "China Environment Yearbook", "Compilation of New China's Sixtieth Anniversary Statistical Data”, "China Statistical Yearbook of Science and Technology”, “China Energy Statistics Yearbook”, “China Population Statistics Yearbook", “China Labor Statistics Yearbook" and some provincial (city, district) statistical yearbooks. In order to compare the regional differences, according to the standards of the National Bureau of Statistics, the 30 provinces, cities and autonomous regions were divided into eastern, central and western regions.

\section{Results and Discussion}

\subsection{Analysis of Green Energy Efficiency Measurement Results}

Table 1 shows the average green energy efficiency of each region from 2000 
Table 1. Average Green Energy Efficiency by Region from 2000 to 2016.

\begin{tabular}{|c|c|c|c|c|c|}
\hline Region & Green Energy Efficiency & Rank & Region & Green Energy Efficiency & Rank \\
\hline Beijing & 0.860 & 2 & Hunan & 0.571 & 10 \\
\hline Tianjin & 0.647 & 6 & Guangdong & 0.829 & 3 \\
\hline Hebei & 0.437 & 19 & Guangxi & 0.427 & 20 \\
\hline Shanxi & 0.331 & 26 & Hainan & 0.607 & 9 \\
\hline Inner Mongolia & 0.392 & 23 & Chongqing & 0.558 & 12 \\
\hline Liaoning & 0.644 & 8 & Sichuan & 0.395 & 22 \\
\hline Jilin & 0.458 & 15 & Guizhou & 0.262 & 28 \\
\hline Heilongjiang & 0.565 & 11 & Yunnan & 0.407 & 21 \\
\hline Shanghai & 1.330 & 1 & Shaanxi & 0.335 & 25 \\
\hline Jiangsu & 0.707 & 4 & Gansu & 0.343 & 24 \\
\hline Zhejiang & 0.705 & 5 & Qinghai & 0.219 & 29 \\
\hline Anhui & 0.455 & 16 & Ningxia & 0.205 & 30 \\
\hline Fujian & 0.645 & 7 & Xinjiang & 0.277 & 27 \\
\hline Jiangxi & 0.488 & 14 & Eastern Region & 0.722 & \\
\hline Shandong & 0.540 & 13 & Central Region & 0.470 & \\
\hline Henan & 0.437 & 18 & Western Region & 0.347 & \\
\hline Hubei & 0.450 & 17 & National & 0.518 & \\
\hline
\end{tabular}

to 2016. Analyzing from the geographical dimension, the national green energy efficiency shows obvious regional differences. With the national average green energy efficiency $(0.518)$ as the benchmark, the eastern region $(0.722)$ is higher than the national general level over the years, while the central (0.470) and western (0.347) are both lower than the national average, especially in the west region. Although the green energy efficiency in the central region is higher than in the western region, the gap is not very clear.

Analyzing from the time dimension, the average level of national green energy efficiency showed a declining trend from 2000 to 2016. Except for Beijing, Tianjin, Jiangsu, Zhejiang, etc., where the level of green energy efficiency was basically stable or increased slightly, the green energy efficiency in most regions has decreased to some extent, leading to a decrease in the average national level of green energy efficiency from 0.585 in 2000 to 0.518 in 2016. On the whole, compared with the rapid increase in economic level, there has been a negative growth in green energy efficiency, reflecting the rapid development of China's economy at the expense of high investment and high pollution. Since the entry into the "Thirteenth Five-Year Plan", the green energy efficiency in the eastern, central and western region has maintained a relatively low rate of growth, indicating that the government has paid attention to resource conservation and environmental governance, and the green economy policy has promoted the green energy efficiency. In general, China's green 
energy efficiency still has great room for improvement.

\subsection{Analysis of Spatial Convergence of Green Energy Efficiency}

Through 3.1 analysis, it is found that there are significant differences in the green energy efficiency of each region. In order to further analyze the characteristics of the differences, this paper analyzes the convergence of the green energy efficiency in China based on economic convergence theory. With reference to the processing methods of Xiusong Shi and Shudong Zhao, when analyzing the convergence, the spatial econometric method was introduced [14]. This paper selects the spatial lag model (SLM).

\section{1) Green Energy Efficiency $\beta$ Absolute Convergence}

In Table 2, $\beta$ is the first-order coefficient of green energy efficiency lag, $\gamma / \lambda$ is the Spatial autoregression coefficient, $\log \mathrm{PL}$ is the value of Log-pseudo-likelihood, $R^{2}$ is the goodness of fit of the fixed effects model.

From Table 2, we can see that, from the national perspective, the regression coefficient $\beta$ is negative, but the statistics are not significant, and the parameters $\gamma / \lambda$ reflecting the spatial correlation are statistically significant at the $1 \%$ level. This shows that although the spatial characteristics of green energy efficiency in China are significant, there is no $\beta$ absolute convergence. In terms of sub-regions, the regression coefficient $\beta$ in the eastern region is negative, indicating that the internal gap of green energy efficiency in the eastern region has gradually decreased, but the statistics are not significant. the $\beta$ values in the central and western regions are all significantly positive, indicating that the internal gap between the central and western regions has gradually expanded.

\section{2) Green Energy Efficiency $\beta$ Conditional Convergence}

To investigate the $\beta$ conditional convergence of green energy efficiency, it is necessary to select several control variables. The control variables in this paper are selected as follows. GDP per capita (G), which study the impact of economic development on the convergence of green energy efficiency, measured in constant prices in 2000 . R \& D input (R), expressed by internal expenditures on $\mathrm{R} \&$ $\mathrm{D}$ expenditures; increasing the $\mathrm{R} \& \mathrm{D}$ expenditures can improve the economic

Table 2. Green energy efficiency $\beta$ Absolute convergence space model.

\begin{tabular}{ccccc}
\hline \multirow{2}{*}{$\begin{array}{c}\text { Models and } \\
\text { Variables }\end{array}$} & National & eastern region & central region & western region \\
\cline { 2 - 5 } & SLM & SLM & SLM & SLM \\
\hline \multirow{2}{*}{$\beta$} & -0.094 & -0.091 & $0.095^{\star}$ & $0.174^{\star}$ \\
& $(0.243)$ & $(0.456)$ & $(0.039)$ & $(0.094)$ \\
$\gamma / \lambda$ & $0.4026^{* * *}$ & $0.2099^{* *}$ & $0.3030^{* * *}$ & $0.4526^{* * *}$ \\
& $(0.000)$ & $(0.016)$ & $(0.000)$ & $(0.000)$ \\
$\operatorname{LogPL}$ & 474.810 & 144.379 & 134.187 & 207.758 \\
$R^{2}$ & 0.177 & 0.372 & 0.251 & 0.546 \\
\hline
\end{tabular}

a. The values in parentheses below the parameter estimates are $\mathrm{P}$ values, ${ }^{\star}$ indicates $\mathrm{P}<0.1$, ${ }^{\star *}$ indicates $\mathrm{P}<$ 0.05 , and ${ }^{* * *}$ indicates $\mathrm{P}<0.01$. 
efficiency and pollution control capacity to micro-enterprises and to some extent, affect green energy efficiency. The level of scientific and technological progress (T) is represented by the three domestic patent grants. The impact of technological progress on energy efficiency is not only reflected in energy application technology, but also in the entire process of the economic system from input to output where energy as a factor of production. When energy technologies and management technologies are improved, energy losses are reduced, so that energy resources can be efficiently allocated and energy efficiency can be improved. Foreign direct investment $(F)$, expressed by the proportion of foreign direct investment in GDP, the inflow of foreign capital can bring the advanced technology and management concept to the local, but at the same time there are also problems such as environmental pollution and resource consumption caused by the relocation of low-end industries. The industrial structure $(S)$ is represented by the proportion of industrial output in GDP, due to the fact that China is in a critical period of industrial restructuring and adjustment and the different energy needs of various industries, the energy efficiency of various industries will also be different.

In Table 3, lnG is the logarithm of GDP per capita, $\ln R$ is the logarithm of $\mathrm{R}$ $\& \mathrm{D}$ input, $\ln \mathrm{T}$ is the logarithm of the three domestic patent grants.

From Table 3 , it can be seen that the regression coefficients $\beta$ are negative in the eastern, central, western, and nationwide, and are statistically significant at

Table 3. Green energy efficiency $\beta$ conditional convergence space model.

\begin{tabular}{|c|c|c|c|c|}
\hline \multirow{2}{*}{$\begin{array}{l}\text { Models and } \\
\text { Variables }\end{array}$} & National & eastern region & central region & western region \\
\hline & SLM & SLM & SLM & SLM \\
\hline$\beta$ & $\begin{array}{c}-0.125^{*} \\
(0.087)\end{array}$ & $\begin{array}{c}-0.101^{*} \\
(0.091)\end{array}$ & $\begin{array}{l}-0.04^{*} \\
(0.082)\end{array}$ & $\begin{array}{c}-0.264^{* * *} \\
(0.003)\end{array}$ \\
\hline $\ln G$ & $\begin{array}{c}0.089^{* * *} \\
(0.024)\end{array}$ & $\begin{array}{l}0.125^{*} \\
(0.055)\end{array}$ & $\begin{array}{l}0.049^{* *} \\
(0.032)\end{array}$ & $\begin{array}{c}0.144^{* * *} \\
(0.001)\end{array}$ \\
\hline $\ln R$ & $\begin{array}{l}0.026^{* *} \\
(0.041)\end{array}$ & $\begin{array}{l}0.059^{* *} \\
(0.036)\end{array}$ & $\begin{array}{c}0.043 \\
(0.379)\end{array}$ & $\begin{array}{c}0.010^{\star * *} \\
(0.004)\end{array}$ \\
\hline $\ln \mathrm{T}$ & $\begin{array}{l}0.012^{*} \\
(0.081)\end{array}$ & $\begin{array}{l}0.003^{* *} \\
(0.042)\end{array}$ & $\begin{array}{c}0.021 \\
(0.393)\end{array}$ & $\begin{array}{c}0.061 \\
(0.442)\end{array}$ \\
\hline $\mathrm{F}$ & $\begin{array}{c}0.105 \\
(0.848)\end{array}$ & $\begin{array}{c}0.184 \\
(0.875)\end{array}$ & $\begin{array}{l}1.199^{*} \\
(0.098)\end{array}$ & $\begin{array}{l}0.122^{\star} \\
(0.083)\end{array}$ \\
\hline S & $\begin{array}{c}-0.187^{*} \\
(0.085)\end{array}$ & $\begin{array}{c}0.225 \\
(0.512)\end{array}$ & $\begin{array}{c}-0.263^{\star *} \\
(0.026)\end{array}$ & $\begin{array}{c}0.076 \\
(0.693)\end{array}$ \\
\hline$\gamma / \lambda$ & $\begin{array}{c}0.391^{\star * *} \\
(0.000)\end{array}$ & $\begin{array}{c}0.222^{\star * *} \\
(0.002)\end{array}$ & $\begin{array}{c}0.335^{\star * *} \\
(0.000)\end{array}$ & $\begin{array}{c}0.393^{* * *} \\
(0.000)\end{array}$ \\
\hline $\log P L$ & 482.240 & 145.770 & 138.890 & 223.930 \\
\hline$R^{2}$ & 0.758 & 0.613 & 0.305 & 0.839 \\
\hline
\end{tabular}

a. The values in parentheses below the parameter estimates are $\mathrm{P}$ values, ${ }^{*}$ indicates $\mathrm{P}<0.1,{ }^{* *}$ indicates $\mathrm{P}<$ 0.05 , and ${ }^{* * *}$ indicates $\mathrm{P}<0.01$. 
the $5 \%$ level, indicating that there is a $\beta$ conditional convergence. The parameters $\gamma / \lambda$ reflecting spatial correlation are statistically significant at the $1 \%$ level, indicating that there is spatial correlation. The level of economic development, $\mathrm{R}$ \& D input, the level of scientific and technological progress, foreign direct investment and industrial structure are the main factors affecting the convergence of green energy efficiency in all regions. Among them, the level of economic development, R \& D input, the level of scientific and technological progress, and foreign direct investment have a positive effect on green energy efficiency in the eastern, central, western, and national areas. The industrial structure has a positive effect on green energy efficiency in the eastern and western regions, and a negative effect on the central region.

\section{Conclusion and Recommendations}

This paper uses the idea of green GDP accounting for reference, selects seven indicators from the perspective of environmental pollution emission and governance to construct an ECI, and brings ECI in economic efficiency measurement model to obtain a green GDP, building a Super-SBM to measure green energy efficiency in China and further construct a spatial econometric model to analyze its convergence. The following conclusions can be reached:

1) At present, the overall green-energy efficiency in China is low, showing the characteristics of the region with high levels in the east and low levels in the west. Since the entry into the "Thirteenth Five-Year Plan", the green energy efficiency has slowly increased.

2) There are significant differences in the green energy efficiency across the country. There is no $\beta$ absolute convergence of the green energy efficiency in the east, the west and the country. But there is $\beta$ conditional convergence of the green energy efficiency in the east, the west and the country. The level of economic development, R \& D input, the level of scientific and technological progress, and foreign direct investment have positive effect on green energy efficiency in the eastern, central, western, and national areas. The industrial structure has a positive effect on green energy efficiency in the eastern and western regions, and a negative effect on the central region.

In order to promote green energy efficiency in China, all regions should take measures according to local conditions. In particular, the eastern region should continuously to increase R \& D input and give full play to its technological advantages. The central region should further optimize the industrial structure, actively import foreign capital and absorb the advanced technology and management experience. The western region should vigorously develop the economy, improve the level of GDP per capita, and actively adopt new technologies to improve energy efficiency.

\section{Acknowledgements}

This work was supported by the grants from 2017 Postgraduate Innovation Spe- 
cial Fund Project of Jiangxi province in China (No. YC2017-S218).

\section{References}

[1] Anonymous (2016) The $13^{\text {th }}$ Five-year Plan Outline of the People's Republic of China for National Economic and Social Development. People's Publishing House, Beijing. http://www.gov.cn/xinwen/2016-03/17/content_5054992.htm

[2] Hu, J.-J. and Wang, S.-C. (2006) Total-Factor Energy Efficiency of Regions in China. Energy Policy, 34, 3206-3217. https://doi.org/10.1016/j.enpol.2005.06.015

[3] Li, L.-B. and Hu, J.-L. (2006) Ecological Total-Factor Energy Efficiency of Regions in China. Energy Policy, 36, 821-833.

[4] Xiong, Y.-T. and Huang, N. (2010) Opening-Up and Energy Technical Efficiency in Industrial Sector: An Analysis Based on Stochastic Frontier Model. Contemporary Finance \& Economics, 9, 89-97.

[5] Hu, A.-G., Zheng, J.-H., Gao, Y.-N., Zhang, N. and Xu, H.-P. (2008) Provincial Technology Efficiency Ranking with Environment Factors. China Economic Quarterly, 3, 933-960.

[6] Wang, Z.-H. and Feng, C. (2015) Total-Factor Energy Efficiency Calculation and Its Influencing Factors Analysis in China. Systems Engineering-Theory \& Practice, 6, 1361-1372.

[7] Zhou, S.-J. and Zhang, G. (2016) A Study on the Regional Comparison of Chinese Total Factor Energy Efficiency Considering Environment Effect. East China Economic Management, 30, 64-67.

[8] Yu, H.-L. (2017) The Measurement of Provincial Green Energy Efficiency Level in the Yangtze River Economic Belt. Statistics \& Decision, 8, 59-62.

[9] Qian, Z.-M. and Liu, X.-C. (2013) Regional Differences in China's Green Economic Efficiency and Their Determinants. China Population, Resources and Environment, 23, 104-109.

[10] Tone, K. (2001) A Slacks-Based Measure of Efficiency in Data Envelopment Analysis. European Journal of Operational Research, 130, 498-509. https://doi.org/10.1016/S0377-2217(99)00407-5

[11] Tone, K. (2002) A Slacks-Based Measure of Super-Efficiency in Data Envelopment Analysis. European Journal of Operational Research, 143, 32-41. https://doi.org/10.1016/S0377-2217(01)00324-1

[12] Shan, H.-J. (2008) Reestimating the Capital Stock of China: 1952-2006. The Journal of Quantitative \& Technical Economics, 10, 17-31.

[13] Wang, Z.-P. (2013) Temporal and Spatial Variation of Regional Green Technology Innovation Efficiency and Simulation. Ph.D. Thesis, Jiangxi University of Finance and Economics, Nanchang.

[14] Shi, X.-S., Zhao, S.-D. and Wu, F.-X. (2009) Analysis of Regional Innovation Efficiency and Spatial Discrepancy in China. The Journal of Quantitative \& Technical Economics, 3, 45-55. 